\title{
Treinamento de Habilidades Sociais para Adolescentes: Uma Experiência no Programa de Atenção Integral à Família (PAIF)
}

\author{
Social Skills Training for Adolescents: An Experience in the Program \\ of Comprehensive Attention to the Family
}

\author{
Mariana de Paula e Silva \& Sheila Giardini Murta* \\ Universidade Católica de Goiás
}

\begin{abstract}
Resumo
Este artigo apresenta uma avaliação do processo de um programa de habilidades sociais para adolescentes vinculados ao Programa de Atenção Integral à Família (PAIF). A intervenção foi feita em 11 sessões grupais psico-educativas, com técnicas cognitivo-comportamentais. Os resultados revelaram satisfação frente à intervenção, principalmente no que se refere à liberdade para se expressar e aos efeitos positivos da intervenção. Os indicadores de comprometimento com o grupo que mais freqüentes foram relatar problemas, relatar sentimentos, explicar a causa do próprio comportamento e oferecer apoio ao colega. Os dados indicam que a intervenção teve um processo bem sucedido, cujos resultados e impactos deverão ser verificados em estudos futuros.

Palavras-chave: Habilidades sociais; adolescência; Programa de Atenção Integral à Família.

Abstract

This paper presents a process evaluation of a social skills program for adolescents from the Comprehensive Attention to the Family Program. The intervention consisted of 11 psychoeducational group sessions, with cognitive behavioral techniques. The results revealed satisfaction toward the intervention, mainly about the freedom to self-expression and the positive effects of the intervention. The most frequent adherence indicators to the group were to report problems, to report feelings, to explain the causes of their own behavior and to offer support to their colleagues. The data indicate that the intervention had a successful process, which results and impact may be verified in future studies.

Keywords: Social skills; adolescense; Program of Comprehensive Attention to the Family.
\end{abstract}

A saúde do adolescente tem sido alvo de preocupações de diversos atores sociais, como gestores em saúde, profissionais de saúde e pesquisadores. Dentre os problemas de saúde de maior prevalência nesta faixa etária da população, encontram-se a gravidez precoce, as doenças sexualmente transmissíveis (DSTs) e o uso de drogas, lícitas e ilícitas (Roe-Sepowitz \& Thyer, 2004). Conforme Jeolás e Ferrari (2003), 18\% das adolescentes brasileiras entre 15 e 19 anos tinham um filho ou estavam grávidas. Em 2003, o Ministério da Saúde notificou 9.758 casos de AIDS. Destes, 17\% são em adolescentes e em adultos jovens, na faixa etária entre 13 e 24 anos (Camargo \& Bárbara, 2004). Dados indicam que o álcool é a droga mais consumida entre os adolescentes e que cerca de $50 \%$ dos adolescentes entre 10 e 12 anos já experimentaram tal droga (Déa, Santos, Itakura, \& Olic, 2004). Os danos causados pela droga incluem desde prejuízos físicos, como doença hepática ou pulmonar, a prejuízos psicossociais,

* Endereço para correspondência: Universidade Católica de Goiás, Centro de Ciências Humanas, Avenida Universitária, 1069, Universitário, Goiânia, GO, Brasil, CEP 74605-010.

Caixa-Postal: 086. E-mail: sheila.murta@pq.cnpq.br como conflitos com genitores, evasão escolar e ansiedade (Schenker \& Minayo, 2005).

Acrescenta-se aos problemas já citados a violência entre e contra os jovens, que é uma das maiores responsáveis pelo alto índice de mortalidade nesta etapa de vida, no Brasil. Esse índice fica evidente quando são avaliadas as estatísticas do Ministério da Saúde referentes aos homicídios. No ano de 1998, ocorreram 40.231 mortes por homicídios; $70 \%$ dos mortos eram jovens, em sua maioria homens, pobres, habitantes de periferias urbanas (Centro LatinoAmericano de Estudos de Violência e Saúde Jorge Careli, 2000). Um dado relevante é que na grande maioria das vezes o agressor e a vítima são homens. As idéias arraigadas de poder, de iniciativa e de imposição de sua vontade ressaltam no homem a postura machista, tanto no aspecto sexual quanto no aspecto social. Assim, o machismo é reafirmado nos pegas de carro, nas brigas de gangues, no uso de drogas e no excesso de velocidade no trânsito (Minayo, 2005).

É urgente, portanto, a realização de programas preventivos para adolescentes. No Brasil, algumas intervenções para a promoção de saúde de adolescentes têm sido publicadas, com foco no comportamento sexual e na saúde (Faustini, 
Novo, Cury, \& Juliano, 2003; Jeolás \& Ferrari, 2003; Maheirie, Urnau, Vavassori, \& Orlandi, 2005), na redução de comportamentos de risco de abuso de álcool (Déa et al., 2004), na gravidez precoce (Silva, Oliveira, \& Franco, 1998), nas habilidades de enfrentamento à situações de risco relativos ao abuso de drogas, à violência, aos acidentes de trânsito, ao início precoce da sexualidade, à relação sexual sem uso de preservativos e gravidez precoce (Gorayeb, Cunha Neto, \& Bugliani, 2003).

Os altos índices de problemas de saúde resultantes de fatores comportamentais indicam a necessidade de se construir habilidades de enfrentamento mais saudáveis entre os jovens. A Organização Mundial de Saúde (OMS) recomenda o desenvolvimento de habilidades de vida, entre elas as habilidades de tomada de decisão, de controle da impulsividade, de pensamento conseqüencial e de habilidades sociais, como estratégias para auxiliar o adolescente a se proteger em situações de risco à saúde (Gorayeb et al., 2003). De fato, o treinamento em habilidades sociais é uma opção teórica e metodologicamente adequada para promoção de saúde na adolescência, conforme indicam estudos anteriores (Amaral, Bravo, \& Messias, 1996; Murta, Del Prette, Nunes, \& Del Prette, 2007). Essas habilidades incluem comportamentos como fazer e responder perguntas, fazer e receber elogios, pedir e dar feedback nas relações sociais, iniciar e manter conversação, fazer e recusar pedidos, manifestar opinião, desculpar-se, expressar sentimentos, lidar com as críticas e com a pressão do grupo, entre outros (Del Prette \& Del Prette, 2001).

Déficits em habilidades sociais em etapa de desenvolvimento como a infância e a adolescência podem comprometer fases posteriores do ciclo vital. Há evidências de que esses déficits estão realcionados a problemas psicológicos como condutas anti-sociais, desajuste escolar, suicídio, problemas de relacionamento e depressão (Del Prette \& Del Prette, 1999, 2005). A melhora no desempenho de habilidades sociais constitui um fator de proteção à saúde e de desenvolvimento do indivíduo (Reppold, Pacheco, Bardagi, \& Hutz, 2002) por favorecer o aumento da autonomia, da auto-estima e do suporte social. Um desempenho social com habilidades sociais pode prevenir comportamentos de risco à saúde, já que pode tornar o adolescente capaz de decidir por si mesmo, de recusar convites danosos à sua saúde e de discordar do grupo em momentos de pressão para uso de drogas, por exemplo. Isso justifica a inserção do Treinamento em Habilidades Sociais (THS) em intervenções para a prevenção e promoção de saúde de adolescentes.

Uma revisão da literatura nacional em THS, produzida entre os anos de 1967 e 2003, identificou 17 programas de intervenção, dos quais seis eram programas em prevenção primária, seis em prevenção secundária e cinco em prevenção terciária (Murta, 2005). Todas as intervenções foram aplicadas em grupo, nos contextos escolar e clínico. A autora sugere explorar o potencial do THS como estratégia de prevenção e promoção de saúde e levá-lo para diversos contextos de atuação em saúde como creches, cursos de formação de profissionais de saúde e programas de atendimento à comunidade. Buscando examinar as possíveis contribuições do THS em novos contextos preventivos, este artigo pretende apresentar uma intervenção para desenvolvimento de habilidades sociais feita em um programa de atendimento comunitário, chamado Programa de Atenção Integral à Família (PAIF). Trata-se de um programa de proteção social básica do Sistema Único de Assistência Social (SUAS). O PAIF destina-se à população em situação de vulnerabilidade social, decorrente da pobreza, da privação e também da fragilidade de vínculos afetivos, sociais e de pertencimento. Foi criado em 18 de abril de 2004 (Portaria $n^{\circ}$ 78) pelo Ministério do Desenvolvimento Social e Combate à Fome (MDS) e visa fortalecer vínculos familiares e comunitários, prevenir a violência, desenvolver a autonomia e implementar ações para geração de emprego e renda por meio de intervenções continuadas. Essas intervenções devem abranger a família em todos os estágios do ciclo de vida familiar e compreendem entrevistas familiares, visitas domiciliares, campanhas socioeducativas, palestras, formação de grupos socioeducativos, oficinas de reflexão e oficinas de convivência (Secretaria Nacional de Assistência Social, 2005). Psicólogos e assistentes sociais são os profissionais responsáveis pela condução destas atividades, de tal modo que os fatores de proteção individuais, familiares e comunitários possam ser favorecidos, com vistas ao fortalecimento do senso de responsabilidade, coletividade, autonomia e participação na vida pública.

As ações desenvolvidas no PAIF e sua filosofia tornamno um contexto ideal para o desenvolvimento de trabalhos preventivos e de promoção de saúde e cidadania. A experiência que será relatada a seguir foi conduzida no PAIF de uma cidade do interior de Goiás. Este artigo descreve uma intervenção grupal focada em habilidades sociais na adolescência e apresenta a avaliação do processo da intervenção, no que se refere às atitudes de satisfação ou à insatisfação dos participantes frente ao programa e quanto ao alcance de metas intermediárias previstas para o programa, consideradas indicadores de comprometimento com o grupo.

\section{Método}

\section{Participantes}

Os participantes foram 12 adolescentes provenientes de famílias de baixa renda cadastradas no Programa de Atenção Integral à Família (PAIF) de uma cidade do interior de Goiás. Destes, sete eram meninos e cinco eram meninas, com idades variando entre 11 e 14 anos. Foram convidados a participar todos os adolescentes de uma das turmas do turno vespertino do Programa de Erradicação do Trabalho Infantil (PETI) da cidade. Este contexto foi escolhido como local para a intervenção pela facilidade em localizar o público-alvo e à possibilidade de reduzir os custos para sua participação, uma vez que a intervenção seria parte das atividades de trabalho do PETI e, assim, os adoles- 
centes não precisariam dispor de um horário extra para participar.

Os pais dos adolescentes também foram convidados para participarem do programa. Participaram dois pais e cinco mães com idades entre 34 e 50 anos e escolaridade entre o Ensino Fundamental e o Ensino Médio. A renda individual dos pais era de aproximadamente um salário mínimo e a maioria não tinha emprego fixo.

\section{Ambiente, Material e Instrumentos}

As sessões aconteceram em uma sala do PETI que continha mesa, cadeiras e um quadro-negro. Foram utilizados material de consumo (lápis de cor, cola, folhas de papel, tinta, revistas, balões e cartolina, dentre outros) e material de uso permanente (aparelho de som e CDs).

Os instrumentos para avaliação do programa incluíram:

Baralho de Sentimentos: são cartões com expressões faciais que demonstram estados emocionais como alegria, tristeza, felicidade, indiferença, confusão, cansaço, satisfação, angústia, irritação, dúvida e preocupação.

Roteiro de Entrevista com os Pais: composto por cinco perguntas dirigidas aos pais sobre mudanças comportamentais observadas nos filhos após a intervenção. As perguntas foram: (a) Você, pai e/ou mãe, percebeu alguma mudança de comportamento significativa em seu filho após a formação do grupo de adolescentes?; (b) Ele apresentou melhora ou aumento em habilidades como expressar carinho, fazer elogios, falar o que está sentindo, contar algo de sua vida, puxar conversa, dar opiniões etc?; (c) Em qual contexto ele apresentou tais mudanças?; (d) Houve alguma mudança no rendimento acadêmico dos adolescentes? E na interação com os professores e colegas?; (e) Quais aspectos ele ainda precisa melhorar?

Checklist de Metas Intermediárias (Murta, 2007): apresenta uma lista de comportamentos, cuja ocorrência durante a sessão deve ser assinalada na linha correspondente a cada comportamento. São eles: relatar problemas, relatar sentimentos, chorar, explicar causas do próprio comportamento e oferecer ajuda a colegas. Esses comportamentos são indicadores de comprometimento dos participantes com o grupo e sua ocorrência é considerada como evidência favorável à adequação do andamento das sessões grupais.

\section{Procedimento}

Os pais dos adolescentes foram convidados a comparecerem a uma reunião no PETI, quando lhes foi solicitada sua permissão para que os filhos participassem da intervenção. Nessa ocasião, foram esclarecidos os objetivos do trabalho, o sigilo e a preservação da identidade dos participantes, o modo de utilização dos dados coletados e a possibilidade de desistência do participante sem nenhum prejuízo para sua permanência na instituição. Este mesmo procedimento foi feito com os adolescentes, no horário normal de freqüência à instituição. Solicitou-se aos pais e aos adolescentes que assinassem o "Termo de Consentimento Livre e Esclarecido", através do qual eles expressam formalmente sua concordância em participar do trabalho.

\section{Programa de Intervenção}

Intervenção com os Adolescentes. A intervenção foi em grupo, do tipo oficina psico-educativa, e foi realizada em 11 sessões de 90 minutos cada. A organização geral do programa, os temas, os procedimentos e a estrutura das sessões consistiram numa replicação de parte do Programa de Habilidades de Vida Para Adolescentes (Murta, 2008). Os temas tratados foram: favorecer a motivação pela mudança, estimular a auto-estima e a auto-eficácia, aprender a arriscar-se para crescer, aprender a identificar e questionar erros de pensamento, prestar atenção na mensagem dos sentimentos, aprender a expressar pensamentos e sentimentos, aprender a fazer amizades, compreender os pais, negociar com os pais, treinar o autoconhecimento e a colaboração entre os colegas, avaliar o programa e estimular a continuidade dos ganhos. As sessões foram compostas por cinco etapas: discussão da tarefa de casa, introdução do tema do dia, atividade central, discussão da atividade e avaliação da sessão. A atividade central consistia na aplicação de vivências grupais, relaxamento, ensaio comportamental e atividades arteterapêuticas. O procedimento adotado em cada sessão será apresentado a seguir.

$O$ primeiro encontro teve como objetivos a apresentação dos participantes e da facilitadora, o estabelecimento do contrato de trabalho e de pesquisa e o esclarecimento de aspectos éticos. Esta sessão visava promover a auto-revelação, experimentar o processo de solução de problemas em grupo e experenciar a negociação no trabalho em equipe. Isso foi feito, primeiramente, através da colagem de figuras representando o passado e o futuro deles; a discussão de tais colagens foi feita por meio de um roteiro de discussão em grupo focal com adolescentes. Em seguida, foi realizado o jogo do balão, que consistia em formar um círculo e sempre jogar o balão para o colega da direita e pegar o balão quando fosse a sua vez. Caso o participante deixasse o balão cair deveria sair do jogo. Essa atividade tinha o intuito de discutir as similaridades entre o jogo e a vida, tais como: iniciativa para lidar com desafios, aproveitar a oportunidade de agir no momento adequado, reações diante da perda e exclusão etc. Logo após, foi realizado o bazar de trocas (Yozo, 1996), que propunha aos participantes imaginarem um bazar imaginário no qual deveriam deixar algo deles no grupo e levar algo do grupo para si. Para a avaliação final, foi apresentado o baralho de sentimentos. Os participantes foram convidados a escolher uma ou mais emoções descritivas do seu estado emocional após a sessão do dia. Este procedimento foi repetido nas sessões seguintes.

$O$ segundo encontro buscou sensibilizar a auto-revelação, desenvolver o auto-conhecimento, estimular a autoestima e a auto-eficácia. Os participantes realizaram a atividade "Explorando minhas habilidades" (Virgolim, Fleith, \& Neves-Pereira, 1999), que consistiu no registro das atividades que "sei que faço muito bem", as atividades que "eu faria bem se tentasse" e as atividades que "eu desejo aprender a fazer muito bem". Em seguida, a facilitadora estimulou todos a se empenharem em desenvolver novas habilidades e a pensar nisso no decorrer da semana. 
Silva, M P. S. \& Sheila Giardini Murta, S. G. (2009). Treinamento de Habilidades Sociais para Adolescentes: Uma Experiência no Programa de Atenção Integral à Família (PAIF).

O terceiro encontro visou informar e sensibilizar para o envolvimento em riscos que levam ao crescimento pessoal e a evitação de riscos à saúde. A sessão teve início com a discussão do que os participantes haviam praticado ao longo da semana quanto à tarefa de casa da sessão anterior. Em seguida foram convidados a dizer quem era o seu ídolo (adaptado de Virgolim et al., 1999) e enfatizou-se os riscos que tais ídolos correram para conquistar esse lugar. Foi simulada a atividade de andar na corda bamba para enfrentar os riscos inerentes à vida. Em seguida, os participantes sentaram em círculo e discutiram questões referentes aos riscos que temos que enfrentar para crescer e como cada um tem se arriscado diante dos obstáculos da vida. A diferença entre os riscos que levam ao crescimento e os riscos à saúde também foi discutida. Por fim, foi feito um treino de respiração diafragmática.

$O$ quarto encontro teve como objetivos estimular o autoconceito positivo, desenvolver habilidades de fazer e receber elogios, apresentar os vários pensamentos disfuncionais e desenvolver habilidades de questionar pensamentos disfuncionais. Iniciou-se com a sondagem da tarefa de casa, o que foi feito como rotina nas sessões seguintes. Em seguida, foi feita a vivência "O que dizem de mim", para trabalhar a habilidade de dar e receber elogios. A atividade consistiu em a pessoa dizer o que achava que as pessoas dizem dela e jogar um rolo de barbantes para alguém que também diria o que achava que os outros pensam dela e assim sucessivamente até que todos tivessem dito e formado uma rede de barbante no grupo. Quando o último participante recebesse o barbante, deveria fazer um elogio ao colega de quem recebeu o barbante e assim sucessivamente, de tal modo que todos experimentassem o fazer e receber elogios. Logo após, foram apresentados vários erros de pensamento ("sou um perdedor", "sei que não serei capaz de fazer este trabalho") e foram feitas perguntas (Ex.: "que evidências há para sustentar esse pensamento?") para auxiliá-los a questionar tais pensamentos. A tarefa de casa proposta foi que os participantes avaliassem quais erros de pensamento estavam cometendo e começassem a questioná-los no decorrer da semana.

$O$ quinto encontro visou discutir situações geradoras de sentimentos como raiva, medo, ansiedade, tristeza e desânimo e sensibilizar para o uso de estratégias saudáveis de expressão desses sentimentos e enfrentamento das situações geradoras. Foi proposto um relaxamento em que os participantes foram instruídos a deitarem em uma posição confortável, respirarem lenta e profundamente, imaginarem-se em um lugar ao ar livre e prestarem atenção nas emoções e sensações vividas durante o relaxamento e a visualização. Ao terminar, propôs-se que todos relatassem o que sentiram em tal experiência. Depois foi distribuída uma folha na qual deveriam dar cor aos sentimentos e localizá-los no corpo humano (adaptado de Heegard, 1991/1998). Os participantes foram instruídos a pintarem no corpo humano impresso na folha as partes do corpo em que eles sentiam as emoções e a escolherem uma cor que representasse cada emoção. Depois, a facilitadora conduziu uma discussão a respeito da função dos sentimentos e da relação entre pensamentos e sentimentos. A tarefa de casa propunha que prestassem atenção nos sentimentos vividos ao longo da semana e quais ações foram praticadas para amenizar os sentimentos desconfortáveis.

$O$ sexto encontro teve como objetivo informar sobre os modos de comunicação passiva, agressiva e assertiva e sensibilizar para a expressão assertiva de pensamentos e sentimentos. Propôs-se que os participantes criassem uma máscara da face humana, representando o seu modo habitual de expressar sentimentos (Liebman, 1994/2000). Quando todos terminaram a máscara, solicitou-se que cada um apresentasse sua máscara e relatasse seu modo costumeiro de expressar emoções. Outra atividade realizada foi a leitura do texto "Diferenças entre comunicação assertiva, passiva, agressiva" (Caballo, 1996). Após a discussão do texto, os participantes foram convidados a fazer um ensaio comportamental das três formas de comunicação e a facilitadora salientou os efeitos benéficos da comunicação assertiva. A tarefa de casa propôs a auto-observação sobre como cada um se comunicava.

$O$ sétimo encontro objetivou a prática do dar e receber feedback, informar sobre as várias habilidades sociais, principalmente as relativas ao fazer e manter amizade, e sensibilizar para o desenvolvimento de habilidades sociais nos vários contextos interpessoais. Foi feita a atividade "Com que bicho me pareço? Com que bicho ele se parece?" Essa atividade consistia em anotar em um papel com que bicho cada um achava que se parecia. Este papel foi dobrado e colocado na mão do facilitador, que redistribuiu os papéis de modo que cada participante pegasse um papel. Depois que cada um abrisse seu papel deveria adivinhar que pessoa se parecia com o bicho escrito no papel e dizer quais as similaridades percebia entre o colega e o bicho. Ao final, todos deveriam dizer com qual bicho se pareciam e por que. Logo após, foi aberta a discussão sobre as habilidades necessárias para se fazer amizades, as quais foram relacionadas com as características de cada bicho citado anteriormente. Um Roteiro de Auto-observação e Prática de Habilidades Sociais foi entregue a cada um para ser respondido em casa.

$O$ oitavo encontro buscou estimular a compreensão de fatores de risco e proteção na vida familiar e sensibilizar para o desenvolvimento de responsividade em relação aos pais. Para discutir o tema "família", foi usada uma colcha de retalhos para representar a diversidade de famílias existentes. Depois perguntou-se aos participantes "Como é a cara da sua família?" Foram discutidas as diferenças de modos de ser família e as possibilidades de mudança em heranças negativas aprendidas com os pais e destes com os próprios pais. Como tarefa de casa, solicitou-se que pensassem em um presente que agradasse ao pai ou a mãe, para que entendessem melhor os gostos e preferências dos mesmos e aprendessem a se colocar na perspectiva do outro.

O nono encontro visou favorecer a expressão saudável da raiva, estimular o uso da comunicação assertiva com os 
pais em situações conflituosas e favorecer a prática de relaxamento como estratégia de controle de tensões. Os participantes foram convidados a fazerem um relaxamento e atribuirem, através da imaginação, cor, forma e peso à raiva experimentada no cotidiano. Logo após, foram instruídos a imaginar essa forma diminuindo e tornando-se de cor mais amena. Após o relaxamento, eles fizeram uma pintura sobre a raiva imaginada e relataram como essa raiva é sentida. A tarefa de casa era praticar pedido de mudança assertivo (eu me sinto... eu penso... eu te peço...).

$O$ décimo encontro teve como objetivo o treino da observação, o autoconhecimento e a colaboração entre os participantes. Para o aquecimento do grupo foi proposta a dinâmica "Quem está no comando" (Silva, 2002), que consistiu na formação de um círculo com os participantes, enquanto um dos membros do grupo ficava do lado de fora da sala. Quando ele entrasse na sala, devia adivinhar quem estava coordenando os diversos movimentos realizados pelos participantes (ex: bater palma) e depois de descobrir voltava para o grupo e dava lugar a outro componente para sair da sala e assim sucessivamente. Essa dinâmica teve a finalidade de enfatizar o papel do líder e descontrair os componentes. Logo após, foi feita a brincadeira da "batata quente" (Silva, 2002), que consistiu em passar uma bola rapidamente para o colega da direita e, quando o facilitador dava a ordem para parar, o participante que estivesse com a bola devia responder a questões como: "Quando estou triste eu..."; "Quem gosta de mim é..."; "Minha pior qualidade é...."

$O$ décimo primeiro encontro intenciou avaliar o programa e estimular a continuidade dos ganhos. Isto foi feito através da repetição do Bazar de Trocas, no qual solicitava-se que deixassem algo deles no grupo e que levassem algo do grupo para eles. O "jogo do balão" também foi reaplicado a fim ressaltar a similaridade entre o jogo e a vida e reforçar a iniciativa para lidar com desafios, aproveitar as oportunidades e agir no momento certo, reagir diante da perda etc. A atividade seguinte foi a construção de duas máscaras, uma que revelasse os sentimentos de quando eles entraram no grupo e outra referente aos sentimentos com o término do grupo. Houve discussão e feedback dos participantes sobre sua satisfação com as atividades propostas e as metas alcançadas. Ao final, a facilitadora distribuiu mensagens e guloseimas e se despediu de todos os participantes.

Intervenção com os Pais. Os pais dos adolescentes participaram de três encontros, quinzenalmente, com duração de uma hora cada, momentos em que foram discutidas habilidades parentais relativas às habilidades sociais educativas, ao uso da disciplina e ao estabelecimento de limites, à expressão de afeto e ao estímulo à autonomia.

\section{Avaliação e Análise dos Dados}

Os relatos obtidos durante a aplicação do baralho de sentimentos, ao fim de cada sessão, foram registrados na íntegra. Ao término da intervenção, os pais foram submetidos a uma entrevista para avaliar as mudanças percebidas em seus filhos. Esses dados verbais, sobre satisfação e insatisfação com o programa, foram analisados através de análise de conteúdo.

Durante todas as sessões de intervenção, a facilitadora do grupo observou a ocorrência de metas intermediárias e preencheu, imediatamente após a sessão, o Checklist de Metas Intermediárias. Foram também registrados os relatos que faziam referência a cada meta intermediária. A análise dos dados relativos às metas intermediárias foi feita por meio da quantificação de ocorrência de cada categoria comportamental.

\section{Resultados}

A análise dos relatos verbais dos adolescentes evidenciou a satisfação ou a insatisfação dos participantes quanto à intervenção através das seguintes categorias: (a) "sentimentos relativos à sessão"; (b) "efeitos percebidos como derivados da intervenção".

A categoria "sentimentos relativos à sessão" diz respeito aos sentimentos e estados emocionais vividos durante a sessão. Alguns relatos incluídos nessa categoria são: "estou feliz porque desabafei na sessão"; "gostei da sessão hoje porque pude falar o que sinto e tirar minhas dúvidas"; "estou saindo feliz da sessão me sinto bem aqui". A segunda categoria foi denominada de "efeitos percebidos como derivados da intervenção" e se refere às mudanças de pensamento e crenças modificadas no decorrer das sessões. Alguns dos relatos são: "eu não queria participar do grupo no começo, fiquei com raiva porque atrapalhava a hora da capoeira, mas agora estou saindo feliz porque aprendi a não xingar e a não bater no colega"; "eu não queria participar porque me falaram que psicólogo trata de doido, mas vi que não é isso e estou saindo feliz porque consegui tirar minhas dúvidas e dizer o que estou sentindo"; "não queria participar desse grupo, mas aprendi a não implicar com os colegas e a escutar mais as pessoas". Não ocorreram relatos de insatisfação com o programa.

Quatro pais se dispuseram a ser entrevistados com o intuito de que fosse avaliada sua satisfação quanto aos efeitos do programa sobre o comportamento de seus filhos. A análise dos relatos verbais revelou que: (a) foram desenvolivdas habilidades sociais, com as subcategorias: "expressar carinho", "fazer elogios", "pedir ajuda", "dizer não" e "puxar conversa" e (b) houve "progresso no desempenho acadêmico", definido como fazer tarefas e participar das aulas. Estes dados e suas respectivas frequiências estão listados na Tabela 1.

A habilidade social que todos os pais relataram ter aumentado e/ou melhorado o desempenho foi "expressar carinho", que pode ser ilustrada através desse relato: "Ela era mais bruta, agora tá mais calma e carinhosa". O "fazer elogios" foi relatado por um dos pais, como revela a fala: "Agora ele elogia mais as comidas que eu faço". A subcategoria "pedir ajuda" também foi percebida por um dos pais e está evidente nesta fala: "Ela sempre foi tímida, mas agora ela solicita mais a minha ajuda e do pai para 
Silva, M P. S. \& Sheila Giardini Murta, S. G. (2009). Treinamento de Habilidades Sociais para Adolescentes: Uma Experiência no Programa de Atenção Integral à Família (PAIF).

fazer as tarefas". O "dizer não" também ocorreu, na opinião de um dos pais, e fica claro na seguinte fala: "Me contou que uma vez uns colegas ofereceram vinho pra ela e ela não aceitou". E, por último, um pai relatou o aumento na habilidade de "puxar conversa," explícito nessas falas: "Fez mais amigos depois que participou desse grupo"; "está mais saída"; "puxa assunto com mais facilidade".

Tabela 1

Freqüência de Relatos de Melhoria em Habilidades Sociais e Desempenho Acadêmico após a Intervenção, na Opinião dos Pais

\begin{tabular}{lc} 
Categorias & Freqüência de relatos \\
\hline Habilidades Sociais & 8 \\
Expressar carinho & 4 \\
Fazer elogios & 1 \\
Puxar conversa & 1 \\
Pedir ajuda & 1 \\
Dizer não & 1 \\
Desempenho acadêmico & 3 \\
\hline
\end{tabular}

Por meio do Checklist de Metas Intermediárias, observou-se a ocorrência de cinco metas intermediárias durante as sessões, consideradas indicadores de comprometimento com o grupo: relatar problemas, relatar sentimentos, explicar a causa do próprio comportamento, oferecer apoio ao colega e chorar. Foram feitos registros de ocorrência por sessão, num total possível de onze ocorrências (isto é, uma ocorrência por sessão, independente do número total de ocorrências, ou frequiência, por sessão ou de quem emitiu o comportamento). Os resultados revelaram a ocorrência de todas essas metas intermediárias durante as sessões. A meta intermediária que ocorreu com maior predominância foi "relatar sentimentos". Algumas falas ilustram essa categoria: "Tenho raiva do J. P. ele me pirraça na escola, me xinga e às vezes me bate"; "tenho raiva do meu pai quando ele acha que sou culpado de uma coisa que eu não fiz"; "odeio o meu pai e acho que minha mãe também odeia". A segunda meta intermediária de maior ocorrência foi "relatar problemas", que consiste no relato de situações referentes a fatores de risco para o desenvolvimento. Por exemplo, "Minha mãe gosta mais do meu irmão do que de mim"; "meu pai bate em mim e na minha mãe, só não bate nos meus irmãos". As metas intermediárias "explicar a causa do próprio comportamento" e "oferecer apoio ao colega" tiveram a mesma freqüência de ocorrências. "Explicar a causa do próprio comportamento" consiste na auto-avaliação e na percepção de seus próprios comportamentos (por exemplo, dificuldade em expressar carinho em função da rejeição dos pais). "Oferecer apoio ao colega" foi definido como oferecer suporte social afetivo, cognitivo ou instrumental para um colega, com vistas a ajudar na possível solução de um problema relatado pelo colega (por exemplo, "quando seu pai te bater, se você quiser pode ir dormir lá em casa"). O "chorar" teve a menor freqüência de ocorrência. Esses dados estão disponíveis na Tabela 2.
Tabela 2

Freqüência de Ocorrência de Metas Intermediárias durante a Intervenção*

\begin{tabular}{lc}
\hline Metas Intermediárias & Freqüência \\
\hline Relatar sentimentos & 11 \\
Relatar problemas & 8 \\
Explicar causas do próprio comportamento & 6 \\
Fornecer apoio ao colega & 6 \\
Chorar & 2 \\
Total & 33 \\
\hline
\end{tabular}

Nota. *número possível de ocorrências por categoria comportamental $=11$.

\section{Discussão}

Este artigo almejou descrever a avaliação de processo de um Programa de Habilidades Sociais, no que se refere às fontes de satisfação e insatisfação dos participantes quanto à intervenção e ao alcance de metas intermediárias indicadoras de comprometimento com o grupo. A intervenção foi avaliada pelos adolescentes como positiva por permitir expressar pensamentos e sentimentos e por gerar sentimentos e sensações agradáveis e a aprendizagem de habilidades sociais. A avaliação dos pais evidenciou uma percepção positiva dos efeitos da intervenção, principalmente sobre a ampliação do repertório de habilidades sociais de seus filhos, incluindo os comportamentos de "expressar carinho", "fazer elogios", "pedir ajuda", "dizer não" e "puxar conversa". Pode-se especular que o desenvolvimento destas habilidades sociais pode funcionar como um fator de proteção para tais adolescentes, promovendo como resultado proximal, relações interpessoais mais gratificantes, maior habilidade para lidar com problemas interpessoais e um senso de auto-estima mais desenvolvido (Reppold et al., 2002) e, como resultado distal, a prevenção de problemas internalizantes e externalizantes (Del Prette \& Del Prette, 2005). A melhora no desempenho de tais habilidades sociais é corroborada por estudos anteriores (Amaral et al., 1996; Murta et al., 2007), que também identificaram aumento no desempenho de habilidades sociais em adolescentes participantes de treinamento em habilidades sociais.

Os resultados referentes ao alcance de metas intermediárias revelaram que todas as metas intermediárias ocorreram. "Relatar sentimentos" e "relatar problemas" foram as categorias que ocorreram com frequiência mais alta. Isso provavelmente aconteceu pelo fato de que ambos os comportamentos foram diretamente encorajados e reforçados, por meio da escuta empática (provável) da facilitadora. Já as metas intermediárias de "oferecer apoio ao colega" e "explicar a causa do próprio comportamento" tiveram uma freqüência mais baixa. Dados acerca da manutenção de participantes em intervenções preventivas mostram que essa manutenção no programa está correlacionada a uma maior participação no programa, entendida como adotar com- 
portamentos de liderança e de oferecer apoio ao grupo (Coatsworth, Duncan, Pantin, \& Szapocznik, 2006). A julgar por estes achados, pode-se dizer que esta intervenção mostrou indícios de estar no caminho certo, por terem ocorrido com alta freqüência relatos de problemas pessoais e de sentimentos, embora ainda se devesse fortalecer a ocorrência de algumas metas intermediárias, como aquelas relativas à aliança terapêutica e ao suporte social no grupo.

Algumas dificuldades foram experimentadas ao longo da implementação da intervenção. A primeira delas diz respeito à pouca adesão ao programa quando de sua divulgação no contexto em que os adolescentes estavam. No início, muitos deles não queriam participar das sessões, o que pode ser atribuído ao desconhecimento sobre a Psicologia e a preconceitos, como "quem precisa de psicólogo é doente mental". Deve-se salientar que o programa foi feito em uma cidade do interior de Goiás, onde a atuação do psicólogo, e em especial do psicólogo na comunidade, é pouco conhecida. Isso sugere que a divulgação de programas desta natureza em ambientes em que a Psicologia é desconhecida requer estratégias específicas a fim aumentar a adesão ao programa (Serxner, Anderson, \& Gold, 2004). Uma segunda dificuldade foi o fato de a intervenção e o registro dos dados terem sido feitos pela mesma pessoa, sem o apoio de um segundo observador, o que teria sido útil também para a verificação da concordância entre observadores. É possível que a realização da intervenção ao mesmo tempo que a observação e o registro dos dados tenha dificultado uma maior precisão das observações feitas. Por outro lado, considerando-se que, tradicionalmente, há uma cisão entre intervenção e pesquisa (isto é, intervenções não são sistematicamente avaliadas, a menos que sejam projetos de pesquisa), pode-se considerar um avanço a busca de uma estratégia de avaliação viável com vistas à conciliação entre intervenção e avaliação. De fato, o checklist, técnica observacional usada, mostrou-se apropriado para o contexto, por ser de aplicação viável e não intrusiva, em oposição a medidas verbais quantitativas, cuja aplicação não foi possível, dada a pouca familiaridade dos adolescentes com a escrita, razão pela qual se buscou o uso de medidas alternativas. Uma terceira dificuldade foi inserir os pais na intervenção e também na avaliação, em função do horário em que os encontros foram realizados, que coincidia com o horário de atividades da maioria.

Como estratégia de intervenção em si, os dados indicam que o processo da intervenção foi satisfatório e gerou benefícios para os participantes. Com base nisto, sugere-se a replicação deste trabalho com outros segmentos da comunidade, como professores de ensino fundamental e médio, os quais poderiam atuar como multiplicadores do ensino das habilidades sociais. Sugere-se, ainda, que o treinamento em habilidades sociais seja parte constante dos trabalhos realizados pelo PAIF, em função do caráter preventivo das intervenções, o que está em plena concordância com os objetivos do programa. Intervenções grupais em habilidades sociais poderão ser inseridas nas oficinas de convivência e reflexão, já previstas na metodologia do PAIF.
Versões futuras deste programa poderiam incluir mais sessões e adicionar habilidades de manejo de estresse e de solução de problemas, aproximando-se mais de um programa de habilidades de vida (Gorayeb et al., 2003). Deste modo, o PAIF poderá se fortalecer ao longo do tempo, a partir do uso de intervenções teoricamente embasadas, metodologicamente viáveis e efetivas. A comprovação desta efetividade deve esperar por estudos futuros, com amostras maiores, delineamento experimental e avaliação de seguimento, a fim de se verificar em profundidade os efeitos deste programa junto a adolescentes em situação de vulnerabilidade social.

\section{Referências}

Amaral, V. L. A. R., Bravo, M. C. M., \& Messias, T. S. C. (1996). Desenvolvimento de habilidades sociais em adolescentes portadores de deformidades faciais. Estudos de Psicologia (Campinas), 13, 31-47.

Caballo, V. E. (1996). Manual de técnicas de terapia e modificação do comportamento. São Paulo, SP: Santos.

Camargo, B. V., \& Bárbara, A. (2004). Efeitos de panfletos informativos sobre a Aids em adolescentes. Psicologia: Teoria e Pesquisa, 20, 279-287.

Centro Latino-Americano de Estudos de Violência e Saúde Jorge Careli. (2000). Morbimortalidade de jovens por causas violentas no Brasil: Uma análise dos anos 90. Rio de Janeiro, RJ: Escola Nacional de Saúde Pública.

Coatsworth, J. D., Duncan, L. G., Pantin, H., \& Szapocznik, J. (2006). Retaining ethnic minority parents in a preventive intervention: The quality of group process. The Journal of Primary Prevention, 27, 367-389.

Déa, H. R. F. D., Santos, E. N., Itakura, E., \& Olic, T. B. (2004). A inserção do psicólogo no trabalho de prevenção ao abuso de álcool e outras drogas. Psicologia: Ciência e Profissão, 24, 108-115.

Del Prette, A., \& Del Prette, Z. A. P. (2001). Psicologia das relações interpessoais: Vivências para o trabalho em grupo. Petrópolis, RJ: Vozes.

Del Prette, Z. A. P., \& Del Prette, A. (1999). Psicologia das habilidades sociais: Terapia e educação. Petrópolis, RJ: Vozes.

Del Prette, Z. A. P., \& Del Prette, A. (2005). Psicologia das habilidades sociais na infância: Teoria e prática. Petrópolis, RJ: Vozes.

Faustini, D M. T., Novo, N. F., Cury, M. C. F. S., \& Juliano, Y. (2003). Programa de orientação desenvolvido com adolescentes em centro de saúde: Conhecimentos adquiridos sobre os temas abordados por uma equipe multidisciplinar. Ciência $e$ Saúde Coletiva, 8, 783-790.

Gorayeb, R., Cunha Netto, J. R., \& Bugliani, M. A. P. (2003). Promoção de saúde na adolescência: Experiência com programas de ensino de habilidades de vida. In Z. A. Trindade \& A. N. Andrade (Eds.), Psicologia da saúde: Um campo em construção (pp. 89-100). São Paulo, SP: Casa do Psicólogo.

Heegard, M. (1998). Quando alguém tem uma doença muito grave. As crianças podem aprender a lidar com a perda e a mudança (M. A. V. Veronese, Trad.). Porto Alegre, RS: Artmed. (Original publicado em 1991)

Jeolás, L. S., \& Ferrari, A. P. (2003). Oficinas de prevenção em um serviço de saúde para adolescentes: Espaço de reflexão e de conhecimento compartilhado. Ciência e Saúde Coletiva, 8, 611-620. 
Silva, M P. S. \& Sheila Giardini Murta, S. G. (2009). Treinamento de Habilidades Sociais para Adolescentes: Uma Experiência no Programa de Atenção Integral à Família (PAIF).

Liebman, M. (2000). Exercícios de arte para grupos: Um manual de temas, jogos e exercícios (R. Migliorini, Trad.). São Paulo, SP: Summus. (Original publicado em 1994)

Maheirie, K., Urnau, L. C., Vavassori, M. B., \& Orlandi, R. E. B. (2005). Oficinas sobre sexualidade com adolescentes: Um relato de experiência. Psicologia em Estudo, 10, 537-542.

Minayo, M. C. S. (2005). Laços perigosos entre machismo e violência. Ciência e Saúde Coletiva, 10, 23-26.

Murta, S. G. (2005). Aplicações do treinamento em habilidades sociais: Análise da produção nacional. Psicologia: Reflexão e Crítica, 18, 283-291.

Murta, S. G. (2008). Programa de habilidades de vida para adolescentes: Manual para aplicadores. Goiânia: Porã Cultural.

Murta, S. G. (2007). Avaliação de processo de um programa de manejo de estresse ocupacional. Psicologia: Reflexão e Crítica, 20, 295-302.

Murta, S. G., Del Prette, A., Nunes, F. C., \& Del Prette, Z. A. P. (2007). Problemas en la adolescencia: contribuciones del entrenamiento en habilidades sociales. In M. R. Ríos-Saldaña (Ed.), Manual de intervención psicológica para adolescentes: ámbito de la salud y educativo (chap. 2). Bogotá, Colombia: PSICOM. Retrieved de http://www.psicomeditores.com/ catalogo.php

Reppold, C. T., Pacheco, J., Bardagi, M., \& Hutz, C. S. (2002). Prevenção de problemas de comportamento e o desenvolvimento de competências psicossocias em crianças e adolescentes: Uma análise das práticas educativas e dos estilos parentais. In C. S. Hutz (Ed.), Situações de risco e vulnerabilidade na infância e na adolescência: Aspectos teóricos e estratégias de intervenção (pp. 10-51) São Paulo, SP: Casa do Psicólogo.

Roe-Sepowitz, D. E., \& Thyer, B. A. (2004). Adolescent mental health. In L. A. Rapp-Paglicci, C. N. Dulmus, \& J. S. Wodarski (Eds.), Handbook of preventive interventions for children and adolescents (pp. 67-84). Hoboken, NJ: John Willey \& Sons.

Schenker, M., \& Minayo, M. C. de S. (2005). Fatores de risco e de proteção para o uso de drogas na adolescência. Ciência e Saúde Coletiva, 10, 707-717.

Secretaria Nacional de Assistência Social (2005). Manual de orientações versão atualizada. Programa de Erradicação do Trabalho Infantil- PETI. Manuscrito não-publicado.

Serxner, S., Anderson, D. R., \& Gold, D. (2004). Building program participation: Strategies for recruitment and retention in worksite health promotion programs. American Journal of Health Promotion, 18, 1-6.

Silva, L. A. V., Oliveira, R. F., \& Franco, A. L. S. (1998). Inserção do psicólogo em programas de atenção primária à adolescência: Uma experiência em Salvador-Bahia. Psicologia: Reflexão e Crítica, 11, 605-620.

Silva, R. C. (2002). Metodologias participativas para trabalhos de promoção de saúde e cidadania. São Paulo, SP: Vetor.

Virgolim, A. M. R., Fleith, D. S., \& Neves-Pereira, M. S. (1999). Toc, toc... plim, plim: Lidando com as emoções, brincando com o pensamento através da criatividade. Campinas, SP: Papirus.

Yozo, R. Y. K. (1996). 100 jogos para grupos. Uma abordagem psicodramática para empresas, escolas e clínicas. São Paulo, SP: Agora. 